\title{
A política do xamanismo e os limites do medo
}

\author{
Robert Storrie \\ Departamento de África, Oceania e Américas - Museu Britânico
}

RESUMO: Os Hoti são um pequeno grupo de caçadores-horticultores que vive na região central da Guiana venezuelana. Neste artigo, examino o que os Hoti entendem por igualdade, hierarquia e poder, bem como o uso coercitivo do medo por indivíduos que cultivam a reputação de "Pessoas Leves" ou seja, pessoas especialmente hábeis em interagir com os poderosos seres do meio xamânico -, um papel que é essencial para a fertilidade e segurança da comunidade. O povo hoti é altamente igualitário e anti-hierárquico em suas concepções morais - e, para eles, todo poder é ambíguo e toda pretensão de autoridade pode levantar suspeitas. Por essa razão, é muito raro que alguém proclame ter habilidades xamânicas, embora cultivar tal reputação sem nunca admiti-la envolva diretamente considerável habilidade política. A política do xamanismo pode ser um jogo exigente, perigoso e às vezes fatal, pois os Hoti serão capazes - por meio do humor, do ridículo e até da violência - de limitar a capacidade dos xamãs de acumular autoridade e exercer poder.

PALAVRAS-CHAVE: Amazônia, Venezuela, Hoti, xamanismo, poder, política.

\section{Introdução}

Os Hoti ${ }^{1}$ são um povo seminômade de aproximadamente 700 indivíduos, que habita um território montanhoso na Serra de Maigualida, região central da Guiana venezuelana. Vivem da caça e da coleta, bem 
como da agricultura de coivara. A maioria de suas terras é dominada pela floresta tropical, com trechos ocasionais de savana, elevando-se em dramáticos espinhaços e serranias, cortados por pequenas ravinas e rios de correnteza rápida. Possuem um território de 10 a 20 mil km², que os vizinhos - os Piaroa, Panare, Hiwi, Yabarana e Ye'kuana - visitam para fazer comércio, às vezes para caçar e pescar - ou, ocasionalmente, para garimpar ouro. $\mathrm{Na}$ época do meu trabalho de campo, ${ }^{2}$ mais da metade de todos os Hoti vivia em uma de duas aldeias de missóes religiosas: uma povoamento da Missão Novas Tribos (MNT) no limite sul de seu território, no rio Caño Iguana, ${ }^{3}$ e outra em Kayamá, na fronteira norte de suas terras, administrada por freiras da Igreja Católica.

Os Hoti talvez sejam o povo mais igualitário já descrito pela etnografia amazônica. Todos os Hoti a quem perguntei concordaram que não havia diferenças fundamentais ou essenciais de aptidão ou inteligência entre homens, mulheres e crianças. Ódio e violência estão excluídos da esfera social. Quase não se ouvem vozes alteradas numa comunidade hoti, a punição das crianças nunca vai além da mais suave repreensão e elas certamente nunca apanham. Seres humanos, dizem os Hoti, sempre são generosos e nunca violentos. Seres humanos não podem matar ou mesmo ferir outros seres humanos, embora nem sempre seja imediatamente óbvio quem é ou não humano. Sua defesa da igualdade baseia-se em concepçôes cosmológicas da natureza das pessoas e da humanidade. Essas concepções sustentam que o aspecto eterno de todos os seres - o ho (plural, hodi) - tem sempre a mesma aparência, as mesmas capacidades e origens, todos são todos coetâneos e, o que é importante, habitam no mesmo universo moral. ${ }^{4}$

Em suas vidas cotidianas, os Hoti demonstram respeito pelos outros e por outros pontos de vista; vivem em comunidades pacíficas que rejeitam todas as formas de dominação ou coerção, ou a autoridade de uma pessoa sobre outra. Entretanto as concepções morais hoti são estrutura- 
das não em termos de ausência de hierarquia, mas antes em termos de resistência à hierarquia. Eles entendem que a manutenção de relações sociais igualitárias em comunidades tranqüilas e harmoniosas é produto do trabalho social. Reconhecem claramente o potencial humano para a cobiça e a violência e para o desejo de poder sobre os outros; potencial que exprimem nos termos de uma natureza transformacional do universo - a possibilidade de um ser humano pacífico e generoso transformar-se em algo outro.

$\mathrm{O}$ povo hoti freqüentemente afirma a equivalência de todos os seres e procura ativamente minar a autoridade e a hierarquia. Quase todos os Hoti a quem perguntei se recusaram a dar algum tipo de declaração normativa acerca da vida social ou de concepções morais - eles não diriam coisas que pudessem ser interpretadas como críticas a outras pessoas. Eles ridicularizam qualquer um que aparente ser orgulhoso ou autoritário e evitam qualquer um que pareça estar zangado ou fale alto, ou demonstre alguma inclinação para a violência. Para os Hoti, uma das características definidoras dos "outros", os não humanos e potencialmente não humanos, é a expressão de uma gama de emoções, todas agrupadas sob a palavra yowali - ira, fúria, cobiça e egoísmo, valentia, loucura ou violência. Uma pessoa não é yowali se é generosa, tranqüila, reservada e temerosa (idiyu). ${ }^{5}$

Apesar de afirmarem a equivalência, o igualitarismo ativo e a exclusão de qualquer violência física das relações interpessoais, morais e sociais, há uma zona da experiência e do saber na qual desigualdade, poder, violência e medo são todos potenciais, ou mesmo, às vezes, essenciais - como no envolvimento deles com os variados e poderosos seres outros-dos-humanos do sempre presente, subjacente, imanente e causal âmbito do xamanismo. $\mathrm{O}$ xamanismo, quer seja utilizado para fins negativos ou positivos, é uma presença bastante real no mundo. Ele não existe como parte de um campo da experiência extraordinária nem é 
visto como pertencente a uma esfera isolada da prática. Todo mundo tem um aspecto xamanístico, o ho, e todos têm acesso direto ao meio xamânico por intermédio dos seus sonhos, a matéria-prima do xamanismo. À noite, antes de irem dormir, todos os adultos comprimem uma forte mistura de tabaco preparado entre a gengiva e o lábio inferior, para que os sonhos sejam mais intensos. A maioria do xamanismo hoti é conduzida desse modo, em sonhos sensitivos. O sonho sensitivo é aprendido desde muito cedo por crianças que ouvem os adultos toda manhã nas malocas - quando os sonhos são recontados, discutidos e comparados. As crianças aprendem a prestar atenção a seus sonhos; quando elas acordam de um sonho intenso ou um pesadelo, dizem-lhes que o que viram é muito importante e é real (cf. Santos-Granero, 2003).

Não há um papel claramente reconhecido de "xamã" nem demonstrações ostensivas de "xamanismo". Há pessoas que são reconhecidas por outras como especialmente hábeis na interação com os Seres de Fora (èo ma hadi). Acredita-se que elas tenham relações muito próximas com os seres outros-dos-humanos - particularmente, com os guardióes Anciãos da Floresta (èo aimo). É muito raro que alguém reivindique ou admita uma vocação especial para xamã, embora cultivar uma tal reputação sem nunca admiti-la diretamente envolva uma habilidade política considerável. Como muitos povos amazônicos, os Hoti são ativamente igualitários e, para eles, todo poder é ambíguo e toda reivindicação de autoridade pode levantar suspeitas. Uma admissão (ou reivindicação) de vocação xamânica pode expor essa pessoa a acusaçôes abertas de bruxaria.

No entanto, algumas pessoas, geralmente homens - mas, às vezes, também mulheres ou mesmo crianças -, podem tornar-se dignas de medo. Por intermédio do envolvimento habilidoso com os seres do universo misterioso, poderoso, transformacional - as fontes de fertilidade e doença -, elas adquirem poderes curativos e letais. Elas usam seu poder para defender a comunidade e algumas podem também tentar utilizar 
suas temidas reputaçóes para manipular ou intimidar outras comunidades hoti; podem até exercer seu poder numa política do medo, capaz de afetar seus próprios co-residentes.

Como os Hoti conciliam a aparente tensão entre seu ethos anti-hierárquico e as capacidades desiguais no exercício do poder xamânico? A resposta está, creio, na concepção do valor atribuído ao "temer" como uma característica humana intrínseca e positiva. Neste ensaio, explorarei os limites morais do uso do medo e as sanções que demarcam e policiam esses limites. Entre os Hoti, quem reivindica o exercício desses poderes embarca em um jogo político perigoso e às vezes fatal.

\section{Universo transformacional}

O xamanismo é essencial ao povo hoti devido à natureza, e incertezas, do universo em que habitam. Como muitos povos ameríndios, os Hoti descrevem um universo transformacional, composto de diversas camadas, onde seres e objetos não necessariamente podem ser conhecidos ou apreendidos a partir de suas aparências. ${ }^{6}$ Ao contrário, o conhecimento da verdadeira natureza de uma pessoa, ser ou objeto pode resultar de seus efeitos, ainda que seja possível que ela nunca venha a ser conhecida. Explorei esse aspecto do pensamento classificatório hoti em outro trabalho (Storrie, 1999, 2003), porém aqui é importante salientar que os Hoti aceitam a possibilidade de diferentes interpretaçóes do mesmo evento ou encontro e que o mesmo ser ou objeto pode ser percebido de modo diferente por pessoas diferentes e, assim, ser classificado diferentemente.

É por essas razões que uma compreensão do universo xamânico se torna tão crucial. Como Rivière descreve para os Trio, "se uma criatura particular é a criatura que de fato se vê, ou um espírito vestindo as rou- 
pas daquela criatura, depende do que resulta do encontro - a menos que a pessoa seja um xamã e, assim, seja capaz de ver, através do disfarce, a realidade interna" (1994, p. 257).

Também para os Piaroa a incerteza é um quebra-cabeças ontológico diário. Para eles,

esses "problemas" de identidade [...] certamente não eram relativos a "metáfora", pois os Piaroa estavam ali obviamente preocupados com a identidade factual: "Esse porco-do-mato é um humano ou um vegetal?"; "Essa onça é um animal, um bruxo humano ou um deus de 'antes do tempo'?"; "Essa borboleta ou morcego é um bruxo de uma comunidade estrangeira?". Se interpretassem mal, entendiam que as conseqüências literais poderiam ser terríveis - o indivíduo poderia ficar sujeito ao ataque de um predador. O Ruwang [o xamã] é quem era capaz de resolver esses mistérios de identidade: era o único capaz de transformar carne de porco, que na verdade era carne humana, em comida vegetal segura; era o único capaz de ver o bruxo na pele de morcego e combatê-lo. (Overing, 1990, p. 610)

O cosmos é povoado por uma grande variedade de pessoas e seres. No pensamento hoti eles não estão divididos em categorias correspondentes às nossas noçóes de "natural" e "sobrenatural", ou de "terreno" e "espiritual". Em vez disso, as qualidades sugeridas por essas categorias estão incorporadas, em graus variados, em todos esses seres. Todos os seres e pessoas, e alguns objetos, têm um aspecto eterno (ho), semelhante à alma, que existe no meio xamânico, geralmente sob uma forma semelhante à humana; bem como um corpo, que é forma distintiva de sua espécie ou tipo. No mundo da experiência de vigília, os Hoti apontam para seus peitos ou estômagos para indicar o ho, que às vezes também é chamado a "coisa animada dentro do coração" (kwo hu kwa ma há) ou a "coisa animada dentro do estômago" (ièo kwa ma ha ). 
Revista de Antropologia, São Paulo, USP, 2006, v. 49 no 1.

Em um nível de explicação, parece haver um lado de dentro e um de fora nas pessoas. O de dentro é o ho, a "alma" eterna, cuja aparência é idêntica a todas as outras "almas"; todas são equivalentes e coetâneas umas às outras. $\mathrm{O}$ de fora é o corpo, que veste a alma e dá a cada ser suas características e aptidōes distintivas. Às vezes, esses seres antropomórficos (o ho, plural, hodì), que são a natureza de suas espécies, podem habitar outros corpos, revelando-se a si mesmos e suas verdadeiras naturezas por meio de comportamentos característicos - ou, antes, por meio do comportamento atípico da forma física que habitam.

No entanto - e significativamente -, não há palavra hoti para "corpo" nem, creio, algum conceito correspondente a nossa idéia de corporeidade (cf. Overing, 1997, p. 2). Os Hoti falam da "pele" (hedodo) e a descrevem como um recipiente ou cobertura para o ho. ${ }^{7}$ Também chamam o ho "a coisa que se vai" (woi deka ha ), referindo-se tanto à partida do ho após a morte quanto à idéia de que, enquanto o "corpo" dorme, a pessoa vivencia o mundo xamânico.

A natureza de uma pessoa ou ser pode modificar-se graças ao efeito de poderosas substâncias sobre o corpo - pela ingestão de carne, por exemplo. ${ }^{8}$ Corpos e naturezas, comportamentos e almas são permeáveis uns aos outros e são tanto fixos como variáveis, dependendo do contexto; tanto o interior como o exterior podem variar e ser o local da diferença. No caso de uma pessoa, por exemplo, que se comporta de maneira imprópria, os Hoti não acreditam que ela tenha sido possuída pelo ho de outra pessoa, mas que sua natureza modificou-se devido ao contato corporal com alguma substância transformadora.

De acordo com Viveiros de Castro, os ameríndios postulam uma continuidade metafísica e uma descontinuidade física entre os seres e o cosmos (1998b, p. 56), ou seja, que há uma "alma" universal e corpos mutáveis. Para os Hoti, entretanto, a possibilidade de que transformações do corpo modifiquem o ser interior parece desafiar a noção de uma 
alma universal. Os Hoti consideram a possibilidade de que a aparência de um ser não forneça prova alguma de sua "natureza", mas os corpos são mais do que "roupas" que incorporam as aptidões e práticas de espécies particulares, e os hodï - "almas" - não são, de fato, claramente dissociados de seus corpos (ver Werlang neste volume). O que está dentro e o que está fora também dependem do contexto - ou ponto de vista. O ho está, para os Hoti, dentro da pele, mas é um èo ma ha, literalmente, "um ser de fora", um aspecto da pessoa que existe "fora" (èo), no mundo xamânico. ${ }^{9}$ O que os Hoti estão descrevendo, em termos de seus encontros vividos com outras pessoas, são (nos termos de Ingold) "pessoas-organismos" (cf. Ingold, 1996, p. 128) que existem como diferentes aspectos com diferentes capacidades, simultaneamente em diferentes mundos. Por exemplo, um ser que existe como porco no mundo da vigília é, simultaneamente, um ho antropomórfico no meio xamânico - e não às vezes uma coisa e outras vezes outra coisa diferente. Sven-Eric Isacsson descreve como os xamãs emberá transformam-se, por meio de canções, de indivíduos a cosmos. As viagens xamânicas que empreendem são feitas dentro de seus corpos - agora não mais pessoais, mas cósmicos. As interpretações de Isacsson são extremamente úteis para nos auxiliar a refletir sobre o potencial do conhecimento cosmológico amazônico sobre indivíduos e corpos e sobre corpos enquanto cosmos (Isacsson, 1993, p. 70).

Os xamãs têm a capacidade de ver simultaneamente todas as transformaçôes possíveis de um ser. Também podem ter o conhecimento de como transformar a si mesmos - possivelmente até mesmo em "outros" perigosos, como uma onça predadora. É no interior desse universo que o conhecimento e os sentidos aguçados dos xamãs ("os que sabem bem", ti anku, ou "Pessoas Leves", ka $\underline{a} \underline{\text { o }}$ hadi) tornam-se questão de vida ou morte. Na maioria das malocas hoti, mora ao menos uma pessoa assim. Elas podem ser, para as outras pessoas, tanto temíveis quanto assombro- 
sas; oferecem uma proteção tranqüilizadora, mas também a possibilidade de poder incontrolado. Um xamã pode perder-se numa transformação, ou ser incapaz de retornar à forma humana - após ter, sob a condição de onça, bebido sangue. Pode até, involuntariamente, atacar seus próprios parentes.

\section{As pessoas leves}

Os Hoti se referem às pessoas que acreditam ser particularmente

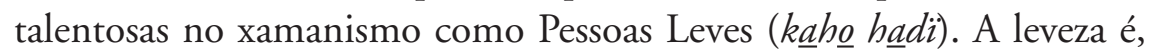

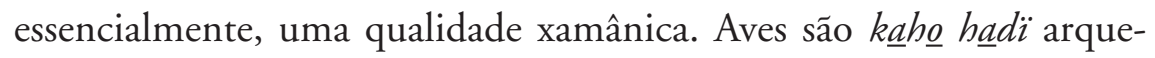
típicos, têm substância - são fisicamente sólidas - mas não são limitadas à terra. São capazes de viajar entre os domínios do cosmos e, quanto a isso, são como k $\underline{a} h \underline{h} h \underline{a} d i$ humanos - que às vezes são descritos voando como aves ou se transformando em aves. Os Hoti manifestam uma especial fascinação por aves e apontam-nas quando elas estão voando, com o braço esticado, dizendo "të, të, të" - "lá, lá, lá".

O peso é tipicamente uma característica de coisas viventes limitadas à terra; corpos são "pesados" e alguns dos seres "outros-dos-humanos" também são referidos como pesados. Os Senhores dos Animais, os aimo, são pesados por causa do aspecto físico dos animais que representam; tal como são os espíritos do Vento e da Água - por causa, dizem os Hoti, do assombroso poder físico desses elementos. Do mesmo modo, "leveza” não é uma característica exclusiva de seres incorpóreos - onças também são "leves", não deixam rastros, a não ser intencionalmente, e também porque são os animais de estimação dos Anciãos da Floresta, os èoaimo, ou mesmo os próprios Anciãos em forma de onça, ou um xamã humano transformado. As onças são especiais, estão sempre associadas ao ambiente xamânico. 
Algumas pessoas nascem leves e demonstram essa aptidão desde a infância. No entanto, conforme as pessoas vão crescendo, ocorre que, para todas elas, a fronteira entre vigília e sono se torna menos definida e elas se tornam mais "leves". É desse estado intermediário entre vigília e sono, entre vida e morte, que a "leveza" dos mais velhos se origina; eles se tornam cada vez mais permeáveis ao ambiente xamânico "de fora". Mas vale lembrar que o "de fora" pode estar localizado dentro da pele. Os corpos das Pessoas Leves são leves em virtude de sua porosidade e permeabilidade. Eles permitem que o universo atemporal passe para dentro desse mundo.

Acredita-se, portanto, que as pessoas leves tenham sentidos tão aguçados que podem perceber o mundo das causas que subjaz ao mundo da vigília; elas podem ver o que uma pessoa ou coisa "realmente" são; elas podem entreter relações próximas com pessoas "outras-dos-humanos" poderosas, que podem ser convencidas a ajudar ou intervir na vida dos Hoti, trazendo proteção e sucesso na caça, ou doença e morte. Podem até se tornar poderosas o suficiente para se transformarem em predadores - tal como a onça. Elas podem percorrer o mundo, através do tempo e do espaço, enquanto seus egos corpóreos permanecem nas redes, junto ao seu próprio coração. Podem fazer com que o hodï de outras pessoas, especialmente dos jovens, se extravie, causando doenças e até a morte. A bruxaria humana pode remover a proteção, deixando o ho da vítima exposto e vulnerável. Acredita-se que algumas pessoas especialmente competentes e maldosas têm a capacidade de tomar o ho de uma pessoa diretamente, mas de modo geral seus poderes vêm da habilidade de convencer seus aliados sobrenaturais a roubar o ho de suas vítimas.

Doença e morte não "acontecem" apenas, são sempre conseqüência de açôes diretas. Os awéladï - sombras, fantasmas ou aspectos do mal -, sempre presentes nos locais mais escuros e na fria umidade da floresta, são os agentes diretos da morte humana. Eles podem matar por 
acidente, com seu toque frio letal, porque sua solidão insuportável levaos a procurar os vivos; ou podem ser os agentes da ira ou maldade humanas, capturando o ho a mando, propositado ou não, de uma Pessoa Leve - alguém que "conhece bem" o mundo xamânico das causas e intervém - seja para proteger seu povo ou para promover seus próprios objetivos e desejos egoístas. Os awéladï só têm chance de matar se a pessoa estiver carente da proteção de seus guardiões, os Anciãos da Floresta. Esses guardióes podem ser convencidos ou ludibriados pelas Pessoas Leves, de modo a negligenciar seus deveres. Todos os Seres de Fora podem reagir àquelas emoções humanas que os Hoti descrevem como yowali. Sentir fortes emoções pode ameaçar a saúde e o bem-estar daqueles que estão à sua volta. A discórdia, ou mesmo a ira velada, ou o ressentimento no interior de um aldeamento, acredita-se, podem trazer riscos a todos. Indivíduos e famílias prefeririam ir-se embora a arriscar brigas que pudessem provocar essas emoções. Para os Hoti, os perigos envolvidos no sentir emoções negativas não estão relacionados apenas aos possíveis perigos físicos, mas também à percepção das conseqüências sobrenaturais da ira, direta ou indiretamente dirigida. $\mathrm{O}$ povo hoti não faz distinção categórica entre violência física e violência xamânica mas, enquanto as pessoas comuns podem ferir acidentalmente por meio de suas emoções caóticas e descontroladas, as Pessoas Leves podem canalizar isso em violência direta.

\section{Bruxaria, generosidade e humanidade}

Passo agora a alguns exemplos de pessoas que dizem ser ou proclamam a si como Pessoas Leves. Uma carreira xamânica como Pessoa Leve apresenta uma variedade de resultados possíveis. $\mathrm{O}$ exemplo ao qual muitos aspirariam é o do ancião e chefe reconhecido de maloca ou comunidade 
- generoso, sábio, respeitado, confiável e, apesar de quieto, assombroso e temível, mas não temível demais. Outra conseqüência possível de se envolver nessa política do medo são o ridículo e o exílio, ou talvez até a morte. É claro que, na verdade, algumas dessas pessoas são tudo isso respeitadas, temidas, ridicularizadas, evitadas ou atacadas - para pessoas diferentes em momentos diferentes.

A generosidade é muito importante para a moral hoti: cobiça e mesquinhez são comportamentos definidores de pessoas que são yowali violentas, zangadas, "Outras". A generosidade, por outro lado, é prova de humanidade: ela demonstra que uma pessoa não há de ser yowali. Desde a primeira vez em que estive entre os Hoti, eles me davam espontaneamente presentinhos de todo tipo - incluindo comida preparada, fruta e mel, bem como miçangas e enfeites de plumagem. Comportavam-se adequadamente, mostrando a própria humanidade e esperando para ver como eu reagiria - testando minha humanidade. A generosidade não é medida apenas em termos materiais, mas também em grau de socialidade, tempo, trabalho e conhecimento. O xamã deve dar sua energia e conhecimento desinteressadamente, para que a comunidade prospere sob sua proteção. Ele é provedor da alimentação, graças a seu envolvimento com os Senhores dos Animais, e da fertilidade humana, graças a suas relações com os Anciãos da Floresta, que guardam as almas dos Hoti que ainda estão por nascer. Assim, conhecimento, prosperidade, fertilidade e generosidade se encontram todos juntos no xamã ideal. A falta de generosidade foi mencionada em todas as discussóes que presenciei que implicavam acusações de bruxaria. 
Revista de Antropologia, São Paulo, USP, 2006, v. 49 no 1.

\section{Itë e Kenowano}

Itë, homem com mais de 50 anos e recém-chegado a Kayamá, era um tanto marginal - sua casa e suas roças ficavam do outro lado do rio, a cerca de dois quilômetros das outras casas hoti, mais próximas da missão. Ele vivia com as filhas e seus maridos e famílias. Era distante e não mostrava interesse em visitar e estabelecer laços com as pessoas da aldeia da missão. Como um estranho, ele deveria se esforçar mais, na opinião dos outros, para conviver com os outros grupos - se quisesse obter algum grau de aceitação e superar a forte suspeita que os Hoti têm em relação a membros de comunidades diferentes. Ele se dizia, com orgulho mas também brincando, uma Pessoa Leve.

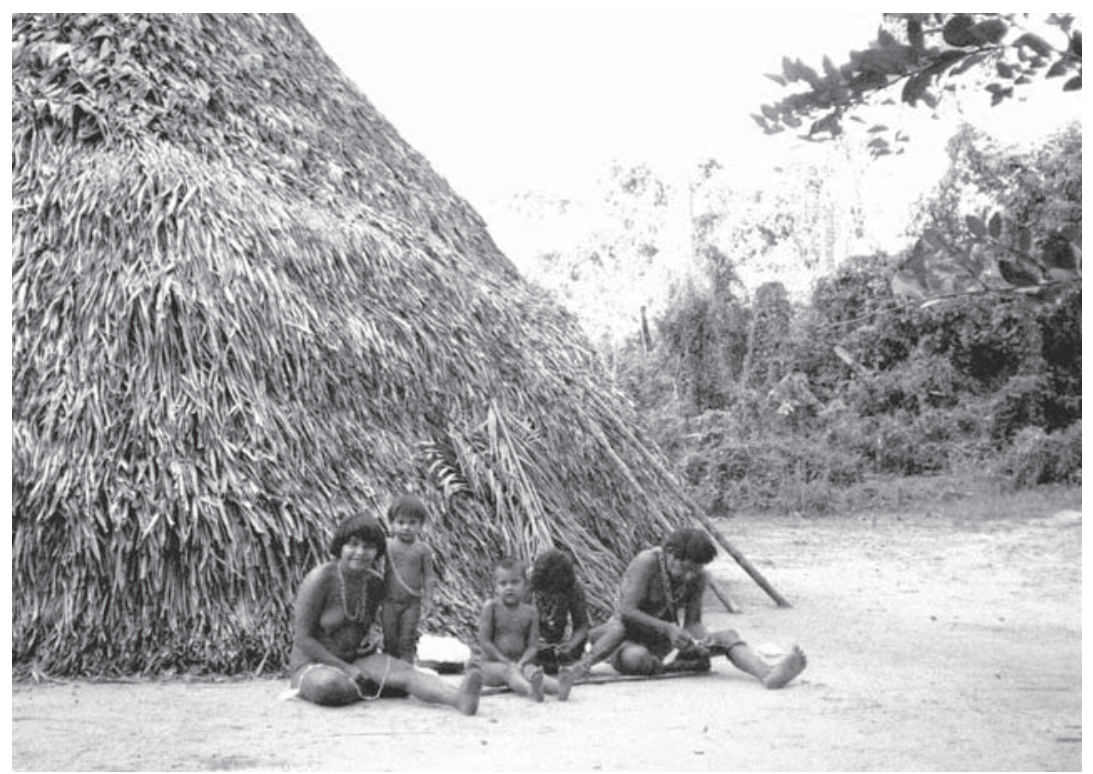

Figura 1: Itë e família. 
Kenowano era um homem importante na comunidade da missão: ele tinha cinco irmãs casadas com homens mais velhos na aldeia, e as freiras o designaram como intermediário entre a missão e a comunidade. Quando a filha de Kenowano morreu subitamente após uma pequena febre, veio à lembrança que Itë fora visto discutindo com a menina na margem esquerda do rio há algumas semanas, e a suspeita de que a ira de Itë tinha sido a causa da morte da menina cresceu entre os membros da família de Kenowano. Esta confrontou Itë e tentou forçá-lo a ir embora. No entanto, eles logo se deram conta de que não tinham o apoio nem mesmo de seus parentes consangüíneos, pois Itë era considerado mais um palhaço do que uma ameaça pela maioria da comunidade, e o assunto foi discretamente abandonado. Itë, por sua vez, depois desse confronto, começou a interagir muito mais com as outras casas da aldeia. Itë e sua mulher até anunciaram a intenção de serem batizados e começaram a assistir aos encontros da igreja, organizados pelas freiras todo domingo. Uma atitude hábil, pois Kenowano era muito próximo à missão - até construíra sua casa dentro do núcleo residencial das freiras. Itë também contribuiu com quase todo o produto de suas roças para um banquete comunal e, com essa mostra de generosidade/humanidade, restabeleceu relações amigáveis com as outras famílias de Kayamá.

\section{Abiyema e Uli Dewa}

Quando interroguei as pessoas de diferentes aldeamentos sobre violência, houve uma concordância geral de que isso era uma característica de "Outras Pessoas" ("Outras Pessoas" pode referir-se tanto a outros Hoti como aos não Hoti). Quando pressionadas, quase todas concordavam que os Hoti ocasionalmente brigavam ou matavam, e muitas dessas pessoas eram capazes de dar exemplos - aparentemente de suas próprias 
experiências. Acumulei alguns relatos de violência fatal e senti que isso apresentava um contraste intrigante com a proibição bem explícita quanto à manifestação, ou mesmo o sentimento, de ira entre os Hoti. Gradualmente, quando consegui me dar conta do caráter subjetivo da onomástica hoti, percebi que muitos desses relatos de violência diziam respeito a uma única rixa entre dois grupos e, provavelmente, a um único incidente. As diferentes histórias constituíam uma série de interpretaçôes diferentes do mesmo fato, distorcido pelas vagarosas teias da fofoca.

Por fim, consegui entrevistar alguns dos que estavam realmente envolvidos na briga. $\mathrm{O}$ que ocorreu não estava, em grande medida, em questão. As diferentes interpretaçôes giram em torno de motivos e justificativas.

A versão dos fatos que circulou pela aldeia da missão em Kayamá, depois de ser visitada por alguns do grupo de Uli Dewa, foi a seguinte: Abiyema, um homem muito velho e bruxo temido, mandou alguns dos seus para matar Uli Dewa, também uma "Pessoa Leve" velha e famosa, que vivia a cerca de três dias de caminhada. $\mathrm{O}$ aldeamento de Abiyema sofrera algumas mortes, e ele se convencera de que Uli Dewa era o responsável. Os enviados - pelo menos dois dos filhos de Abiyema, duas mulheres e outros -, armados com lanças e facóes, chegaram do lado de fora da casa de Uli Haiye à noite e disseram a ele e a seu pai, Uli Dewa, que saíssem; os dois, sabiamente, ficaram dentro de casa. Os atacantes entraram e, na luta, Uli Dewa e outra pessoa da casa foram feridos. Uli Haiye conseguiu desarmar ao menos um atacante e, com a lança deste, matou três deles e feriu um ou mais. Entre os mortos, estava uma mulher (que atacara Uli Dewa com um facão).

Outra versão difundida da história conta que o grupo de Abiyema estava visitando Uli Haiye sobretudo para comerciar. Pediram e receberam facões, facas e panelas, mas, quando exigiram zarabatanas, Uli Haiye disse que não havia. Obviamente, era mentira, pois sempre 
Storrie, R. A política do XAMANismo e OS Limites DO MEDO

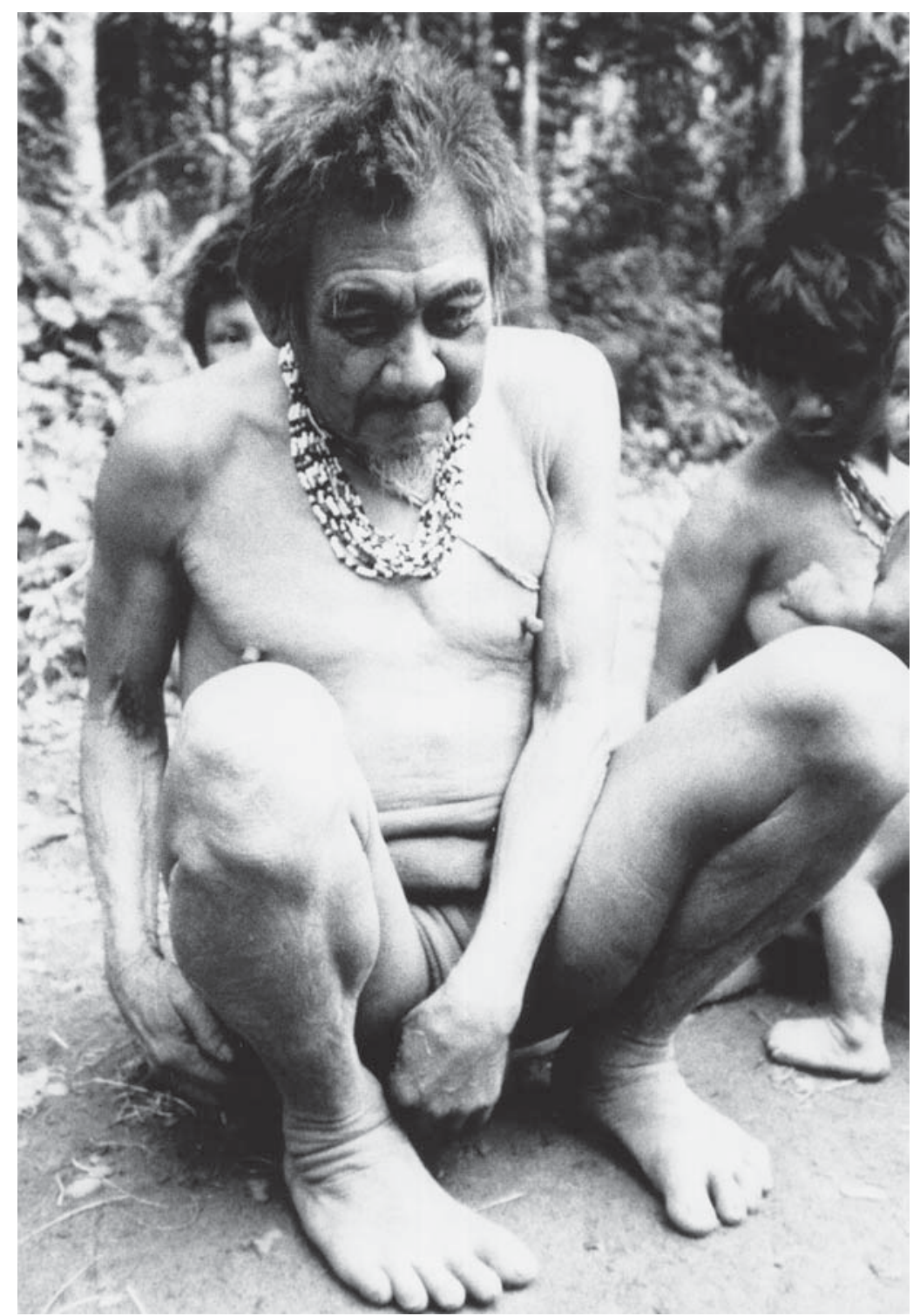

Figura 2: Abiyema. 
há zarabatanas numa casa hoti. Os convidados eram muito exigentes e muito insistentes. Finalmente, a insistência para que lhes dessem zarabatanas foi, para Uli Haiye, a gota d'água. De acordo com diferentes versões da história, ou a recusa provocou imediatamente a discussão que levou à briga, ou os convidados foram embora, voltando depois para atacar os ex-anfitriōes. Os dois velhos, posteriormente, retiraramse para acampamentos na floresta, distantes um do outro, com a maioria de suas famílias.

Esse argumento, tipicamente, funde acusações de bruxaria com falta de generosidade, com os dois lados ansiosos para demonstrar que foram generosos. Bruxaria e loucura são, em muitos contextos, intercambiáveis em controvérsias - embora esta, que resultou em algumas mortes, foi, de longe, a mais séria de que tomei conhecimento.

\section{Kuèo e Kamaya}

A casa e as roças de Kuèo localizam-se numa encruzilhada, no centro do território hoti. Ele vive com a esposa e cinco filhos jovens em uma casinha abobadada, bem abrigada das noites frias, comuns a mil metros acima do nível do mar. Ele mora onde antes morou seu pai, em uma pequena chapada bem abaixo da montanha mais alta da Serra de Maigualida. Kuèo e seus visitantes chamam essa montanha de huana inéwa, a Montanha da Zarabatana, e nos caibros de sua casa sempre há feixes do valioso caniço utilizado para fazer zarabatana. Como ocorre com muitos chefes de povoamentos isolados, Kuèo tem a reputação de Pessoa Leve e bruxo entre as pessoas da aldeia da missão de Caño Iguana, que fica ao sul, a dois dias de caminhada a passo rápido. $\mathrm{O}$ caminho não é muito definido nem utilizado com freqüência, mas é conhecido por ser a única via ligando as duas missões, Caño Iguana e Kayamá. Todo 
ano, uma ou duas vezes, alguém fará essa viagem - e, quando a fizer, sempre irá parar na casa de Kuèo, para trocar caniços de zarabatana. Outro caminho liga Kuèo e seus caniços aos rios a oeste e, no limite, aos Yabarana e Piaroa. A gente de Kuèo sempre viveu nesse lugar e sempre foi o primeiro elo na cadeia que fornece zarabatanas para além dos grandes rios. Sua reputação de Pessoa Leve serve para dissuadir muitas pessoas que pensam em empreender suas próprias expedições para cortar caniços, embora haja alguns que não se impressionem ou julguem que também têm antigas pretensões ao território e que Kuèo não representa uma ameaça.

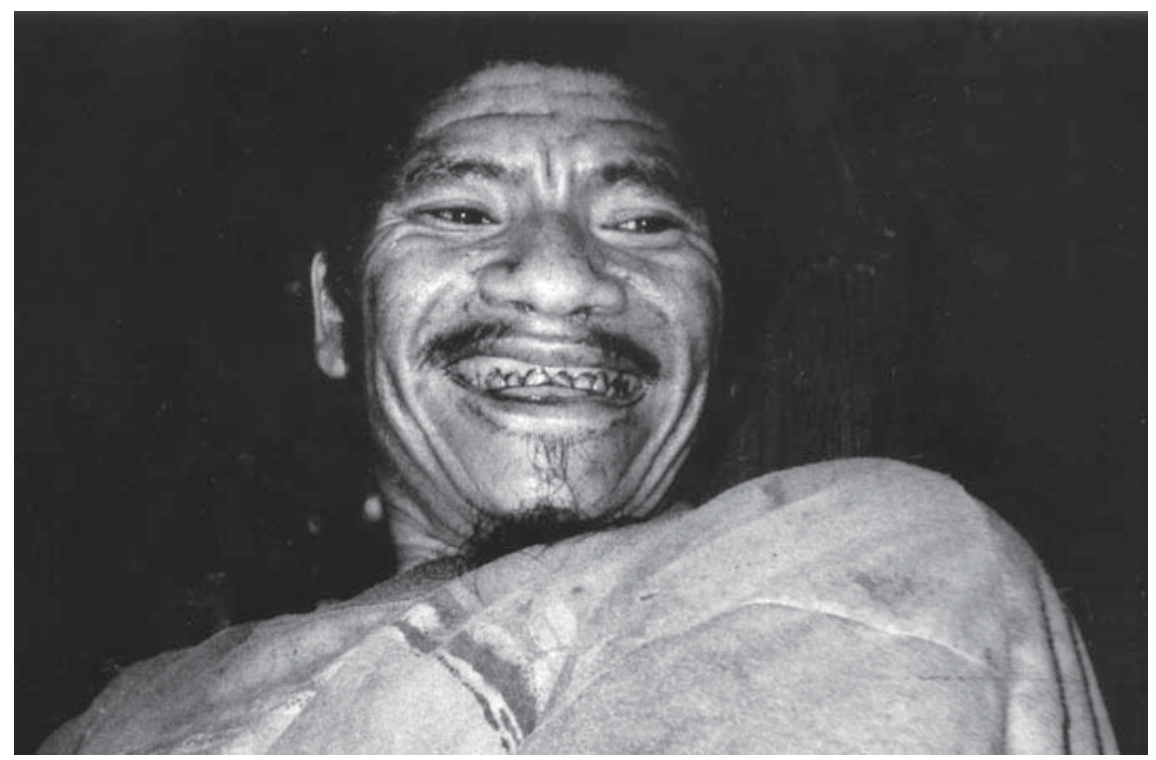

Figura 3: Filho de Hani Kamaya. 
Revista de Antropologia, São Paulo, USP, 2006, v. 49 no 1.

Uma das ocasiōes em que o visitei foi quando viajei com Maièo, Tamuha e Kwaièa, homens de Caño Iguana. Íamos visitar a aldeia de Kayamá. Meus companheiros pararam para pernoitar e construíram um pequeno abrigo em frente à casa dele. Passamos a noite comparando e admirando zarabatanas. Tamuha estava particularmente ansioso para levar caniços para comerciar em Kayamá. Ele e Kuèo retiraram os caniços de três a quatro metros de comprimento um a um, dobraram-nos, examinaram-nos, discutiram sobre seus méritos relativos e finalmente os puseram todos de volta nos caibros. Na manhã seguinte, ocorreu o mesmo, embora no meio da manhã, Tamuha selecionara uma meia dúzia de caniços que considerou os melhores. Kuèo não pediu nada em troca nem se fez oferta alguma.

Um mês depois, voltando pelo mesmo caminho, nós paramos mais uma vez no lado de fora da casa de Kuèo. Tamuha não conseguira trocar todos os caniços que levara, tampouco adquirira tanto curare quanto esperava dos Panare. Agora, Kuèo fazia seus pedidos e todos lhe deram alguma coisa. Um pote de curare e um amolador de Tamuha, uma lança de Maièo, uma faca de Kwaièa e mais uma faca de Hani Kule, um homem de Kayamá que nos acompanhou na viagem de volta, para visitar a família em Caño Iguana. Acomodamo-nos para passar a noite, com o anúncio de Maièo de que ficaríamos todo o dia seguinte, para negociar mais zarabatanas. $\mathrm{Na}$ manhã seguinte, contudo, os visitantes mudaram de idéia e se apressaram em partir. Eles explicaram que Kuèo fora yowali ("violento", "zangado" etc.), levantaram acampamento e partiram o mais rápido possível.

Nessa mesma viagem com Maièo, Tamuha e Kwaièa, paramos por uma noite na única outra casa, fora a de Kuèo, que há no caminho de dez dias entre as duas missóes. Eu estava cansado, faminto e feliz por chegar ao aldeamento de Hani Kamaya. Hani Kamaya, um homem de quarenta e tantos anos, forte e disposto, de barba rala e pele clara man- 
chada de tinta preta em algumas partes, nos recebeu com uma cabaça de hidromel, que nos entregou sem fazer cerimônia. Ele e a família ficaram então batendo papo com meus companheiros por uma ou duas horas, até escurecer, quando voltaram para dentro de suas casas e fecharam a porta para dormir. Fizemos nosso acampamento num puxado à guisa de cozinha, pegado junto à casa, e passamos a noite fria amontoados ao redor do fogo. Na manhã seguinte, levantamos acampamento rapidamente e partimos logo depois do amanhecer. $\mathrm{Na}$ ocasião, eu não comentei ou percebi muito bem a falta de hospitalidade. Eu estava acostumado a ser recebido de modos muito diferentes em diferentes aldeamentos - às vezes desabrida e amigavelmente, outras vezes, com mau humor e suspeição. Na viagem de volta, contudo, mais de um mês depois, chegamos à casa de Hani Kayama de novo no fim do nosso segundo dia de caminhada de Kayamá. Paramos e presumi que passaríamos a noite lá de novo - mas após alguns minutos, Maièo levantou seu cesto, ajeitou a correia na testa e se afastou a passos largos do aldeamento, resmungando para mim que essa gente era ruim e perigosa e que eles iriam tentar nos envenenar se ficássemos. Em vez de ficar, prosseguimos até depois de escurecer, algo que geralmente não se faz quando se viaja pela floresta, e acampamos numa depressão desconfortável e alagadiça.

Maièo explicou para mim que Hani Kamaya não nos dera comida e que isso era uma mostra do seu caráter. Era razoável temer que essa falta de generosidade demonstrasse intenções maldosas. Hani Kamaya é temido pelas pessoas de Kayamá como feiticeiro, e elas não permitem que ele as visite; mas ele tem um histórico de contato com alguns dos grupos estabelecidos em Caño Iguana, o que significa que Maièo não estava imediata ou necessariamente predisposto a acreditar na maldade de Hani Kamaya. Maièo pode ter sido influenciado pelos preconceitos de nossos anfitrióes durante nossa estadia em Kayamá, mas foi a prova clara de mesquinharia que o convenceu do perigo de Hani Kamaya. Além 
disso, Hani Kamaya não bebera primeiro da cabaça de hidromel antes de passá-la a nós - uma cortesia obrigatória para assegurar intenções amigáveis aos convidados. Dada a associação entre generosidade e honradez entre os Hoti, é provável que a mensagem recebida por Maièo fosse exatamente a que Hani Kamaya pretendeu transmitir. Em nossa primeira visita, o próprio Hani Kamaya, orgulhosamente, me disse que a gente de Kayamá tinha medo dele. Um dia depois, dois dos filhos de Hani Kamaya nos alcançaram e anunciaram que voltariam conosco até Caño Iguana.

Tanto Kuèo como Hani Kamaya podiam viajar até as aldeias das missões ou mesmo se aventurar muito além do território de suas casas. Eles conquistaram e cultivaram reputaçôes temíveis e certamente não eram ridicularizados ou considerados engraçados por outros Hoti. Apesar de suas reputaçóes, não eram capazes de atrair muitos seguidores e mesmo seus filhos adultos partiram para se juntar a outros aldeamentos mais próximos das missões.

Tanto Kuèo como Hani Kamaya eram temidos porque meus companheiros sentiram que eles eram yowali. Qualquer um pode se tornar yowali e em muitas circunstâncias não é intrinsecamente imoral ser yowali - por causa de dor ou doença, ou pela ação de outros, que deixam você zangado, ou por causa da solidão. Além da falta de generosidade ser uma indicação de que alguém é yowali, querer ficar sozinho também é yowali. A rejeição intencional da socialidade e da convivência é equiparada à mesquinharia. Kuèo e Hani Kamaya foram os dois condenados à solidão por seu poder e sua reputação, e também condenados por sua solidão, que confirmou sua natureza anti-social. Tanto Kuèo como Hani Kamaya estavam fora de qualquer disputa: a reputação de seu poder fora para além do território hoti e, embora estivessem isolados, foram efetivamente exilados de todas as possibilidades de troca e socialidade fora de suas próprias malocas. 
Storrie, R. A política do Xamanismo E OS Limites Do MEdo

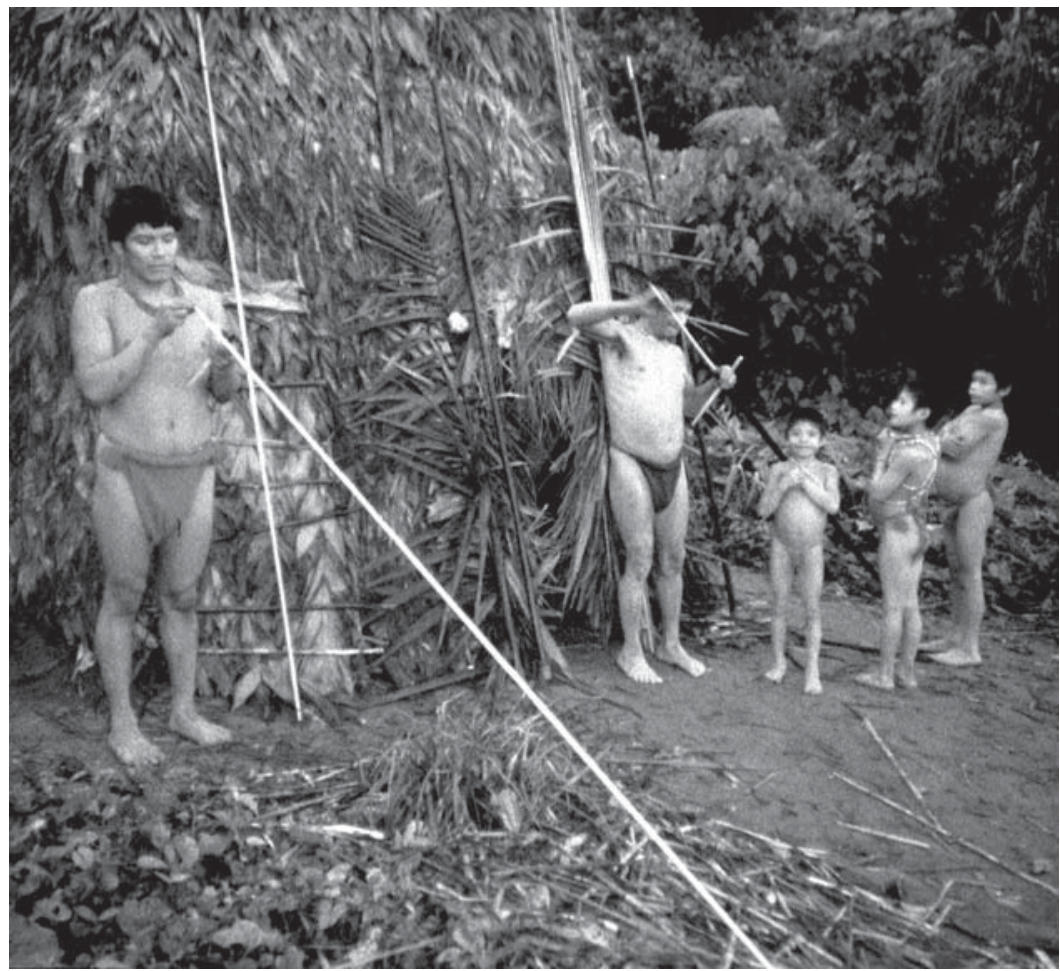

Figura 4: Kuèo. 
Revista de Antropologia, São Paulo, USP, 2006, v. 49 no 1.

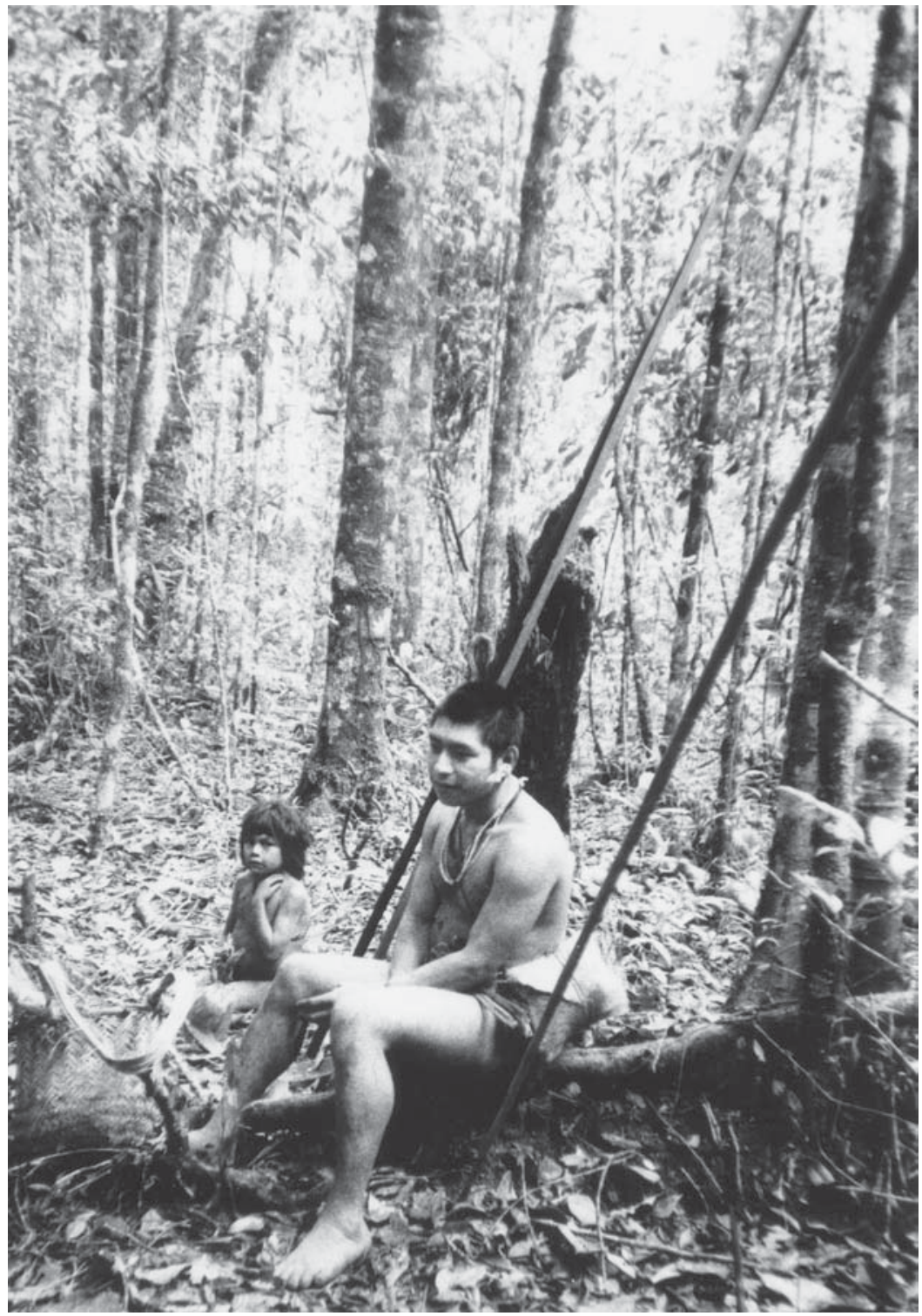

Figura 5: Kuèo e Tamuha. 


\section{Timoteo, Icu Dodo e Kwaica}

Timoteo é reconhecido por todos na aldeia da missão de Caño Iguana como alguém que "sabe bem" (ti anku) - e como uma "Pessoa Leve". $\mathrm{O}$ fato de sua opinião, enquanto autoridade no comportamento dos Seres de Fora, "outros-dos-humanos", ser acatada com unanimidade é um indício de uma considerável reputação de habilidade xamânica, que vai muito além do Vale do Iguana. Timóteo não é velho; quando o conheci, tinha mais de 30 anos. Ele é sossegado, humilde e sorridente, a seu jeito, e raramente fala em público. Reconhecendo sua posição e inteligência considerável, os missionários da MNT treinaram-no como enfermeiro, de modo que ele se tornou responsável por uma síntese entre a cura biomédica e a xamânica. A casa dele é muito visitada e, portanto, come-se muito por lá. Ele e a família se esforçam para ser bons anfitriōes.

Também em Caño Iguana, havia dois irmãos, Icu Dodo e Kwaica. $\mathrm{Na}$ época deste relato, tinham 18 e 16 anos. Pareciam com outros adolescentes hoti - aproveitando a liberdade para serem ora crianças ora adolescentes, conforme desejavam. Eles chamaram minha atenção por serem diferentes dos outros adolescentes, devido ao resultado de uma série de eventos muito anormais. Icu Dodo e Kwaica marcaram uma reunião na casa de Timoteo e deram a estranha declaração de que "iriam ensinar". Essa foi a primeira de algumas reuniōes que marcaram durante um período de cerca de um mês, entre outubro e novembro de 1996, que contaram com a presença de quase todos da aldeia. As reuniōes começavam com os meninos dando instruções sobre bom comportamento, direcionadas sobretudo às crianças. Havia ampla concordância por parte da assembléia quanto ao que diziam. "As pessoas não devem pegar comida da roça dos outros"; "as pessoas não devem pegar as coisas sem pedir primeiro". Crianças eram chamadas individualmente à frente da 
Revista de Antropologia, São Paulo, USP, 2006, v. 49 no 1.

assembléia para serem repreendidas. Gradualmente, as instruções começaram a incluir adultos jovens e, depois, os velhos - Icu Dodo e Kwaica criticavam-nos por terem casos amorosos, ${ }^{10}$ por serem maus maridos, por ameaçarem deixar a comunidade. As reuniōes também se tornaram um fórum para decidir sobre casamentos entre os jovens adolescentes. Fiquei surpreso com a paciência dos Hoti em tolerar por todo esse tempo um comportamento tão sentencioso e ditatorial, que, em qualquer outro contexto, seria completamente inaceitável aos Hoti.

Icu Dodo e Kwaica começaram a fazer ameaças: disseram que os caçadores deveriam sempre procurá-los antes de ir atrás dos animais, caso contrário poderiam morrer em algum acidente. Icu Dodo disse que iria acompanhar os caçadores (em espírito). Disse também que iria arrancar o ho do estômago de qualquer um que se opusesse a seus ensinamentos. Estava a fazer claras ameaças de morte.

Eu comparei algumas anotações com as de um dos missionários da MNT, e ele concordou que isso nunca acontecera. Nos vinte anos que vivia lá, nunca vira reunião alguma nem testemunhara críticas públicas a nenhum membro da comunidade, tampouco ameaças como essas feitas no interior de uma comunidade. ${ }^{11}$

Os dois meninos se declararam kaho hadi, Pessoas Leves, e os dois foram amplamente reconhecidos como tal desde muito novos. Icu Dodo, em particular, demonstrava essa capacidade desde que era muito pequeno. Sua mãe disse que soube quando ele tinha apenas alguns anos de idade, por causa de sua capacidade de ter sonhos prescientes - isto é, mostrar conhecimento e experiência de outros lugares, tempos e acontecimentos. Por exemplo, ele era capaz de predizer, com sucesso, aos caçadores o movimento e a futura localização da caça.

Durante as reunióes, Timoteo ficava sentado em silêncio bem à vista dos outros, endossando o comportamento dos meninos. Todavia, após algumas dessas reuniōes em sua casa, discretamente, fez saber que Icu 
Dodo e Kwaica estavam "ensinando o pensamento deles próprios". Muitos membros da comunidade estavam com a impressão de que a mensagem moral dos meninos vinha dos missionários, com o apoio de Timoteo. Sua intervenção teve o efeito da explosão de uma bolha e solapou a autoridade que os meninos tinham. Embora algumas velhas tivessem manifestado ceticismo durante toda preleção de Icu Dodo e Kwaica, depois da intervenção de Timoteo, as anciãs fizeram longos discursos e envergonharam publicamente os meninos. ${ }^{12}$

Os meninos foram humilhados, e Kwaica aproveitou para ir comigo em uma caminhada de seis semanas para evitar a vergonha. "Temo ser visto" (we idiyu), ele disse. O emprego do termo idiyu é interessante: uma pessoa não é yowali se for idiyu - ou seja, generoso, tranqüilo, reservado e temeroso. Parece que, mediante a intervenção de Timoteo e das anciãs, essas emoções e os valores fundamentais à socialidade verdadeiramente humana lhe foram novamente infundidos.

Ameaças de violência xamânica são levadas muito a sério - e a comunidade estava temporariamente desequilibrada por esses xamãs adolescentes, que, ao cabo, solaparam a própria autoridade crescente por inaptidão política. De fato, o ethos anti-hierárquico dos Hoti tornou impossível que eles minimizassem as pretensóes dos meninos por causa da idade, da inexperiência ou mesmo por explícita inaptidão política. Tiveram de tratá-los com respeito, como iguais, até o momento em que o comportamento deles se tornasse ameaçador demais para ser tolerado. Os meninos passaram de indutores de assombro a aterradores quando ameaçaram arrancar as almas de qualquer um que se opusesse a eles. 
Revista de Antropologia, São Paulo, USP, 2006, v. 49 no 1.

\section{Medo e riso}

A autoridade é medida em parte pelo alcance da aceitação, por outras pessoas, dos relatos dos sonhos de alguém, da interpretação dos próprios sonhos ou dos sonhos dos outros - como uma visão mais ou menos verdadeira. Essa autoridade, por sua vez, apóia-se tanto na utilidade prática das informações fornecidas pelo sonho (por exemplo, para curar ou identificar a localização da caça) como numa sensibilidade política bem agu$\mathrm{da}$, que equilibra socialidade com "assombro".

Como eu disse, os Hoti são altamente igualitários. A autoridade é só passageira; ela logo retrai, manifestando-se em momentos isolados de assentimento. A autoridade de uma pessoa reside naqueles momentos em que os outros aceitam a sua versão como uma interpretação precisa, mas a experiência pessoal de seus seguidores sempre solapa essa autoridade, e esta nunca pode ficar presa à hierarquia.

As narrativas cosmológicas hoti concentram-se em histórias pouco lisonjeiras que ridicularizam os poderosos seres outros-dos-humanos, criadores do mundo físico onde os Hoti agora habitam. Essas histórias repetem, em estilo "pastelão", a corriqueira mensagem amazônica de que o poder enlouquece. ${ }^{13}$ Os deuses foram levados à loucura pelos poderes que exerciam e se tornaram palhaços, que toda noite são motivo de piada para os contadores de história hoti. O mesmo destino aguarda qualquer um que busque o poder à custa dos outros. Pessoas que estão na posição de líder já são engraçadas. Dar ordens faz os outros rirem. Ainda assim, em muitas comunidades há pessoas de quem não se pode rir, que não podem ser ridicularizadas; pessoas que, apesar de não darem ordens, são líderes. Essas Pessoas Leves, que "sabem bem”, detêm um respeito que se sustenta no medo. E aqui retornamos à questão central deste ensaio: a contradição entre acumular e exercer um poder baseado na ameaça de violência (xamânica) e as concepções hoti que deixam cla- 
ro que é imoral fazer outras pessoas sentirem medo, que é imoral tentar controlar os outros, e que a falta de generosidade é imoral. Um xamã que tente controlar os outros induzindo medo está usando seu poder e conhecimento de modo egoísta e mesquinho. ${ }^{14}$

\section{O sublime e os limites do medo}

Do exemplo acima, está claro que há limites ao poder xamânico que uma pessoa pode acumular e um limite ao medo que ela pode induzir nos outros. Ser temeroso é ser humano (cf. Howell, 1989, p. 45). Estar temeroso é uma condição valorizada, uma condição que afirma a humanidade. Entretanto, o povo hoti não aceita um comportamento alheio capaz de causar tanto temor e humildade a ponto de constituir uma ameaça a suas vidas. Caso isso ocorra, é moralmente justificável defender-se, inclusive com violência. Como vimos nos exemplos acima, xamãs que induzem o medo arriscam-se a se tornar objeto de brincadeiras humilhantes e até de serem atacados com lanças e facões.

Em noções do sublime, encontramos uma linguagem para tratar do assombroso e do temível. Para Edmund Burke, a raiz do sublime é o medo e o terror. Tal medo é provocado, explica, pela obscuridade, pelo poder e pela infinitude. $\mathrm{O}$ xamã, do alto de seu poder, tem a habilidade de convencer os que estão à sua volta de que pode perceber as infinitas transformações do meio xamânico, que para os outros são obscuras. Essa habilidade é de fato sublime, nos termos de Burke. É por isso que casas de xamãs bem-sucedidos e generosos são centros vibrantes de convivência, onde a paisagem mítica do Lado de Fora e os disparates absurdos dos criadores são conjurados em risos e visões flamejantes. Esse sublime é irresistível, atraente e altamente social, mesmo que também seja assombroso e indutor do medo. Nas palavras de Burke: 
[...] se o medo e o terror estiverem tão modificados a ponto de não serem de fato nocivos, se a dor não levar à violência e o terror não for congênito à própria destruição da pessoa, enquanto essas emoções liberarem os fragmentos, sejam finos ou grosseiros, de um perturbador ou perigoso estorvo, elas serão capazes de produzir deleite; não prazer, mas uma espécie de horror delicioso, uma espécie de tranqüilidade com um toque de terror, que, por dizer respeito à autopreservação, é uma das mais fortes paixões. Seu objeto é o sublime. Seu grau mais alto, eu chamo de pasmo; os graus inferiores são assombro, reverência e respeito, que a própria etimologia das palavras mostra de que fonte derivam e como se distinguem do prazer positivo. (Burke apud Eco, 2004, p. 293)

Vimos que os xamãs hoti podem ser considerados sublimes, mas quando suas ações revelam uma intenção perigosa (seja mesquinha ou diretamente ameaçadora), seus conhecimentos não mais induzem na comunidade uma sensação de assombro e segurança, antes parecem ameaçadores. Para entender esse deslocamento, podemos invocar a imagem kantiana da tempestade sublime, que a distância inspira excitação e deleite. "Nuvens de raio amontoam-se na abóbada celeste, carregadas de trovôes e relâmpagos... [e] o ilimitado oceano se alevanta com força rebelde [...] é o que há de mais atraente por sua temeridade.” Mas, quando a tempestade se aproxima e a posição do observador não é mais distanciada e segura, ela atinge um ponto em que a ameaça imanente suplanta o sublime (id., p. 295). Quando a temeridade chega muito perto, quando "se transforma em violência", quando o povo hoti sente que eles ou sua comunidade estão realmente ameaçados, então eles podem reagir, e de fato reagem à ameaça da violência xamânica, respondendo com suas lanças. ${ }^{15}$ 


\section{Conclusão}

Os Hoti vivem em um universo transformacional em que a experiência cotidiana dos seres que os rodeiam é potencial e ambígua. Os Hoti reconhecem que há diferentes níveis de compreensão, quando confrontados com esse quebra-cabeça ontológico. Acreditam que as pessoas consideradas "Leves" tenham a visão mais clara do ambiente xamânico. A importância da experiência individual para os Hoti classificarem os seres e os objetos que encontram significa que não há expectativas quanto a uma "verdade" final ou a uma ortodoxia. Os xamãs demonstram grande habilidade em convencer os que estão à sua volta de que seu conhecimento produzirá resultados eficazes. Por causa disso, com freqüência, eles se tornam centro de socialidade e demonstram grande generosidade - não apenas no sentido material de dividir alimento e dar acesso a bens que podem ser trocados, mas também em termos de conhecimento. Esse conhecimento é usado para curar e proteger suas comunidades, para encontrar caça abundante e para assegurar a fertilidade humana. No entanto, como foi mostrado nos exemplos acima, nem todos os xamãs são politicamente hábeis e alguns têm dificuldade em manter a posição.

Devido a seu grande saber, as Pessoas Leves são objeto de assombro e respeito, e o poder que detêm é claramente problemático numa sociedade tão igualitária. Suas comunidades obviamente valorizam e adquirem segurança com sua presença, mas outros grupos podem achá-las intimidadoras e mesmo aterrorizantes. Para um xamã, a dificuldade está em manter a reputação de poderoso e ao mesmo tempo renovar a confiança das outras pessoas quanto a sua generosidade e boa vontade perenes. As Pessoas Leves são com frequiência temidas por seus parentes consangüíneos próximos e co-residentes - embora, no caso de Kuèo e Hani Kayama, suas reputações levaram-nos a tal isolamento que suas próprias famílias se afastaram em busca de comunidades onde houvesse maior 
Revista de Antropologia, São Paulo, USP, 2006, v. 49 no 1.

socialidade e convivência. O regozijo com o sublime é uma explicação da tolerância dos Hoti quanto ao medo induzido por xamãs poderosos. Entretanto, essa tolerância, como mostrei, tem limites.

Para os Hoti, todos têm um aspecto xamânico e qualquer um, potencialmente, dispõe de habilidades xamânicas, como é claramente mostrado pelo exemplo dos xamãs adolescentes, que eram Pessoas Leves desde a infância. Portanto, todos estão em condição de julgar as pretensões ao xamanismo (ver Londoño Sulkin neste volume). O reconhecimento como Pessoa Leve, contudo, não é algo a que a maioria aspire ou, ao menos, não é algo a que uma pessoa possa de modo ostensivo aspirar. Para um xamã perdurar numa comunidade, ele não deve declarar abertamente sua habilidade, mas apenas permitir que esta lhe seja imputada, o que geralmente requer uma habilidade política apurada. O povo hoti luta contra a hierarquia e não tolera o exercício manifesto da autoridade. Nesse contexto, o poder xamânico é ambíguo - ele é essencial à sobrevivência e à contínua fertilidade e, ao mesmo tempo, o seu exercício põe em risco a convivência tranqüila, altamente apreciada. Os xamãs que proclamam abertamente suas proezas xamânicas e, por conseguinte, sua capacidade de violência fatal, são fisicamente impedidos de se aproximarem de outros aldeamentos dos Hoti. Caso se aproximem, provavelmente serão reclassificados e mortos como letais predadores não humanos.

Os Hoti preservam a importância da experiência pessoal na interpretação e classificação do mundo e não se curvam a nenhuma autoridade ou ponto de vista final. Participam da negociação coletiva e social das narrativas que descrevem a natureza do mundo em que vivem e as ameaças que enfrentam - inclusive os Outros, indutores do medo, em todas as suas formas. Os Hoti podem limitar, por meio do humor, do ridículo e até, se for preciso, da violência, a capacidade daqueles que aspiram a xamãs para acumular autoridade e exercer poder. 


\section{Notas}

1 O nome Hoti é o mais utilizado para designar esse grupo na Venezuela desde os anos 1970 e deriva do nome hodï ( $h o$ + sufixo plural animado dì). Não é, a rigor, uma autodenominação, pois a palavra ho significa "pessoa", ou ser senciente, e não necessariamente distingue os Hoti de outros humanos, ou os humanos de outras pessoas (animais ou seres sobrenaturais). Os Hoti não têm um nome objetivo para eles mesmos enquanto grupo; em vez disso, referem-se a "Eu", "nós", "a gente” ou "meu povo".

2 O trabalho de campo em que este ensaio se baseia foi realizado entre abril de 1994 e março de 1997.

3 Em outubro de 2005, o presidente da Venezuela, Hugo Chávez, ordenou a expulsão do pessoal da Missão Novas Tribos do país. As quatro famílias da MNT residentes em Caño Iguana obedeceram a ordem antes do prazo limite, 12 de fevereiro de 2006.

4 Ver Storrie (2003) para um exame da relação entre classificação e concepções cosmológicas.

5 Signe Howell (1989, p. 45) descreve algo muito semelhante para os Chewong da Malásia, para quem "ficar zangado não é ser humano, mas ter medo é".

6 Ver também, por exemplo, Overing (1981, 1990), Black (1977), Rivière (1994), Viveiros de Castro (1992, 1996, 1998a, 1988b), Londoño Sulkin (2000, 2005).

7 Ver Belaunde, Lagrou, Rosengren e Santos-Granero, neste volume, sobre idéias similares entre outros povos nativos amazônicos.

8 Ver Londoño Sulkin, neste volume, para um exemplo comparativo.

9 A palavra èo traduz diretamente a palavra "fora", como em "fora de casa"; também pode significar "floresta" ou "céu" e se refere ao mundo dos sonhos e dos seres outros-dos-humanos. Nesse sentido, também pode significar "fora do tempo" ou "fora de forma”.

10 Os Hoti não distinguem "casamento" de "casos amorosos"; a maioria dos Hoti terá filhos com pelo menos três pessoas durante seu período de vida, e pode ter várias relaçôes conhecidas simultaneamente. Os meninos parecem ter aprendido essa noção com os missionários.

11 D. Rodman (1996), comunicação pessoal.

12 O que também é extraordinário. Normalmente, mesmo as crianças mais levadas não são submetidas a punição tão severa. 
13 Ver Joanna Overing, neste volume, para uma exploração detalhada dos gêneros lúdicos do grotesco empregados pelos Piaroa, vizinhos próximos dos Hoti.

14 Curiosamente, todos aqueles que podiam ser vistos como xamãs egoístas ou mesquinhos eram homens. Conheci três mulheres que eram reconhecidas como xamãs respeitáveis, e todas eram consideradas exemplares em sua generosidade.

15 Para uma discussão sobre a natureza do sublime e de seu lugar para a compreensão da política contemporânea do medo, ver White (2005, p. 187-202).

\section{Bibliografia}

BLACK, Mary B.

1977 "Ojibwa Taxonomy and Percept Ambiguity", Ethos, vol. 5(1): 90-118.

ECO, Umberto

2004 On Beauty: A History of a Western Idea, Londres, Secker and Warburg.

HOWELL, Signe

1989 "To Be Angry Is Not To Be Human, But To Be Fearful Is': Chewong Concepts of Human Nature", in HOWELL, Signe \& WILLIS, Roy (ed.), Societies at Peace: Anthropological Perspectives, Londres, Routledge, pp. 79-99.

INGOLD, Tim

1996 "Hunting and Gathering as Ways of Perceiving the Environment", in ELLEN, R. F. \& FUKUI, K. (ed.), Redefining Nature: Ecology, Culture and Domestication, Londres, Berg, pp. 117-55.

ISACSSON, Sven-Erik

1993 Transformations of Eternity: On Man and Cosmos in Emberá Thought, tese de doutorado, Universidade de Göteborg.

LONDOÑO SULKIN, Carlos D.

2000 "Though it Comes from Evil, I Embrace it as Good: Social Sensibilities and the Transformation of Malignant Agency among the Muinane”, in OVERING, Joanna \& PASSES, Alan (ed.), The Anthropology of Love and Anger. The Aesthetics of Conviviality in Native Amazonia, Nova York, Routledge, pp. 170-86. 
Storrie, R. A política do Xamanismo e os limites do medo

2005 "Inhuman Beings: Morality and Perspectivism among Muinane People (Colombian Amazon)", Ethnos, vol. 70(1): 7-30.

OVERING, Joanna

1981

"Review Article: Amazonian Anthropology", Journal of Latin American Studies, vol. 13: 151-64.

1989 "Styles of Manhood: An Amazonian Contrast in Tranquillity and Violence", in HOWELL, Signe \& WILLIS, Roy (ed.), Societies at Peace: Anthropological Perspectives, Londres, Routledge, pp. 79-99.

1990 "The Shaman as a Maker of Worlds: Nelson Goodman in the Amazon", Man, vol. 25(4): 602-19.

1997 The "Conscious I", the Life of Desires, and the Attachment to Custom: A Piaroa Theory of Practice, comunicação apresentada no "49th International Congress of Americanists".

RIVIÈRE, Peter G.

1994

"WYSINWYG in Amazonia", Journal of the Anthropological Society of Oxford, vol. 3: 255-62.

SANTOS-GRANERO, Fernando

2003 "Pedro Casanto's Nightmares: Lucid Dreaming in Amazonia and the New Age Movement", Tipiti, vol. 1(2): 179-210.

STORRIE, Robert

Being Human: Personhood, Cosmology and Subsistence for the Hoti of Venezuelan Guiana, tese de doutorado, Universidade de Manchester.

2003

"Equivalence, Personhood and Relationality: Processes of Relatedness among the Hoti of Venezuelan Guiana", Journal of the Royal Anthropological Institute, vol. 9(3), p. 407-28.

TAUSSIG, Michael T.

1991 Shamanism, Colonialism, and the Wild Man: A Study in Terror and Healing,

Chicago, University of Chicago Press.

VIVEIROS DE CASTRO, Eduardo

1992

From the Enemy's Point of View: Humanity and Divinity in an Amazonian Society,

Chicago, University of Chicago Press. 

Anthropology, vol. 25: 179-200.

1998a "Cosmological Deixis and Amerindian Perspectivism", Journal of the Royal Anthropological Institute, vol. 4: 469-88.

1998b "Cosmological Perspectivism in Amazonia and Elsewhere", palestras genéricas, Departamento de Antropologia Social, Universidade de Cambridge, 17 fev-10 mar.

WHITE, Curtis

\begin{abstract}
The Hoti are a small group of hunter-horticulturalists living in the highlands of central Venezuelan Guiana. In this article I examine Hoti understandings of equality, hierarchy and power and the coercive use of fear by individuals who cultivate a reputation as "Light Ones" - that is people especially skilled in their interaction with the powerful beings of the shamanic environment - a role that is essential for the safety and fertility of the community. Hoti people are highly egalitarian and anti-hierarchical in their moral understandings and for them all power is ambiguous, and all claims to authority can arouse suspicion. For this reason it is very seldom that anyone will claim ability as a shaman, although there is considerable political skill involved in cultivating such a reputation without ever admitting to it directly. The politics of shamanism can be a demanding, dangerous, and sometimes deadly game, as Hoti people are able, through humor, mockery and even violence to limit the capacity of their shamans to accumulate authority and wield power.
\end{abstract}

KEY-WORDS: Amazonia, Venezuela, Hoti, shamanism, power, politics.

Tradução de André Pinto Pacheco.

Aceito em fevereiro de 2006. 